\title{
Knowledge and Awareness of Serial Extraction Among Undergraduate Students
}

\author{
Rinieshah Nair R. Baskaran', Dhanraj Ganapathy ${ }^{2}$ and Subhashree R ${ }^{3}$ \\ ${ }^{1}$ Saveetha Dental College, Saveetha Institute of Medical and \\ Technical Science, Saveetha University, Chennai - 77, India \\ ${ }^{2}$ Professor and Head of Department, Department of Prosthodontics, Saveetha Dental College, \\ Saveetha Institute of Medical and Technical Science,Saveetha University, Chennai - 77, India \\ ${ }^{3}$ Senior lecturer, Department of Prosthodontics, Saveetha Dental College, Saveetha Institute \\ of Medical and Technical Science, Saveetha University, Chennai - 77, India
}

\section{ABSTRACT}

Serial extraction is defined as the extraction of teeth within the dental arch, to allow space to be available for the remaining teeth. The effect of such an extraction can have a positive and a negative reaction towards the remaining dentition. According to TM. Grabier, serial extractions are a guided, progressive removal of deciduous teeth preceding the time that they would normally shed.A questionnaire composed of 10 structured questions with multiple choices were distributed via an online survey platform - Survey Planet. Total of 100 responses were recorded and analysed.The results obtained were tabulated and represented in the form of graphs. Most of them are aware about serial extraction, there are some who are still unclear about the concept and facts.

\section{KEY WORDS: SERIAL EXTRACTION, DENTAL ARCH, GUIDED, ORTHODONTICS, CORRECTIVE STAGE.}

\section{INTRODUCTION}

The fundamental aspect of orthodontics is to correct the alignment of the teeth for better form and function of the dentition(Kocyigit et al., 2019). In order to achieve that, various studies have been done to ensure that there can be more than one way of addressing each problem in terms of malocclusion(Meador, 1982; Jayade, 2016). They include, crowding, spacing, increased overjet, increased overbite, decreased overjet, decreased overbite, maxillary protrusion, mandibular protrusion, maxillary retrusion,

\section{ARTICLE INFORMATION}

*Corresponding Author: dhanraj.@saveetha.com

Received 13th June 2020 Accepted after revision 8th August 2020

Print ISSN: 0974-6455 Online ISSN: 2321-4007 CODEN: BBRCBA

Thomson Reuters ISI Web of Science Clarivate Analytics USA and Crossref Indexed Journal

\section{Clarivate
Analytics}

NAAS Journal Score 2020 (4.31) SJIF: 2020 (7.728)

A Society of Science and Nature Publication,

Bhopal India 2020. All rights reserved.

Online Contents Available at: http//www.bbrc.in/

Doi: http://dx.doi.org/10.21786/bbrc/13.7/79 mandibular retrusion, etc('Malocclusions, Dental', 2012; Bs, Phulari and Naik, 2017).

Out of the many ways to correct the aforementioned anomalies, the method of which this article highlights is serial extraction which falls under the corrective stage of orthodontics(Kumar, 2007; 'Serial Extraction', 2010). Serial extraction is defined as the extraction of teeth within the dental arch, to allow space to be available for the remaining teeth(Salzmann, 1966). The effect of such an extraction can have a positive and a negative reaction towards the remaining dentition(Ringenberg, 1964). According to Yoshihara, serial extractions are a guided, progressive removal of deciduous teeth preceding the time that they would normally shed, or to be more precise, the fundamental phenomena of adaptability and adjustment(Bfd and Bfd, 1976; Yoshihara et al., 2000).

In terms of adaptability, providing room in the jaw span to harmonize the previously defective tooth system with the normal muscle and bone systems is clearly a 
justification for serial extractions(Joondeph and Riedel, 1976; Yoshihara et al., 2000). For example, a deciduous first molar is extracted to allow room for the permanent premolars to erupt(Hinrichsen, 1961). In accordance with adjustment and previous scenario, if the length of the arch is inefficient, with the help of the previously attained diagnostic information the first premolars are extracted to allow the distal migration of the canine into its anatomical position(Wagner and Berg, 2000; O’Shaughnessy et al., 2011).

The advantage of a serial extraction based treatment is to anticipate and minimise the development of a completely matured deformity in a set of permanent dentition(Lian and Karlsen, 2004). Previously our department has published extensive research on various aspects of prosthetic dentistry ('Evaluation of Corrosive Behavior of Four Nickel-chromium Alloys in Artificial Saliva by Cyclic Polarization Test:An in vitro Study', 2017; Ganapathy, Kannan and Venugopalan, 2017; Jain, 2017a, 2017b; Ranganathan, Ganapathy and Jain, 2017; Ariga et al., 2018; Gupta, Ariga and Deogade, 2018; Anbu et al., 2019; Ashok and Ganapathy, 2019; Duraisamy et al., 2019; Varghese, Ramesh and Veeraiyan, 2019), this vast research experience has inspired us to research about the knowledge and awareness of serial extractions among undergraduates. In the light of the subject, this study is aimed to evaluate the knowledge and awareness of serial extractions among undergraduates and to assess how well the undergraduate students are equipped with theoretical procedures.

Figure 1: The questionnaire that was designed to conduct this survey via Survey Planet.

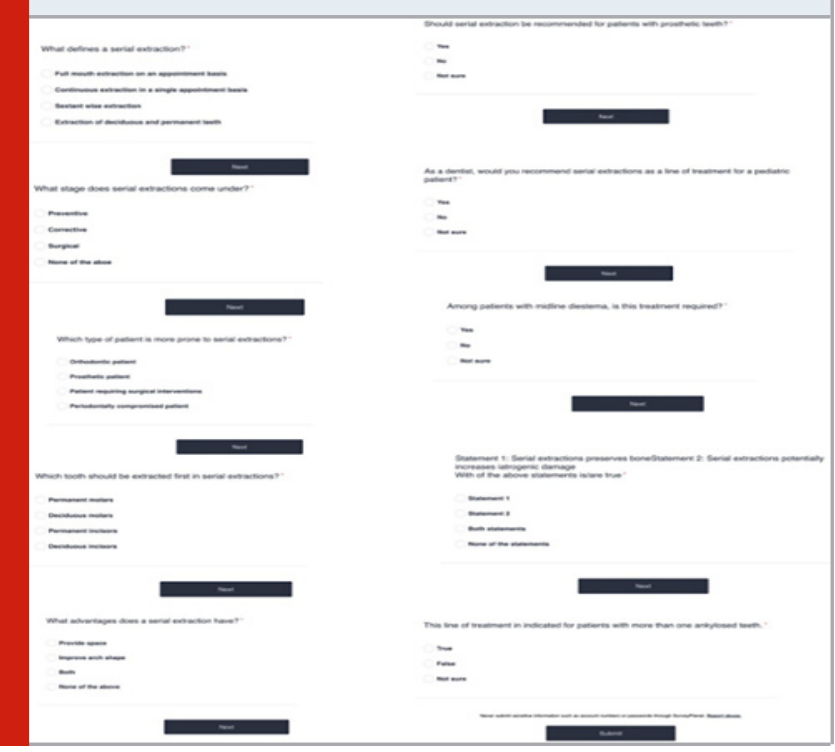

\section{MATERIAL AND METHODS}

This is a KAP survey based on an online setting. A questionnaire consisting of 10 questions were put up online via SURVEY PLANET. The questionnaire was distributed via a web link that was obtained from the website among undergraduates through whatsapp. The data was updated on the website every time someone attempted the questionnaire. The results obtained were then made into pie charts and the data was tabulated based on percentile value.

Graph 1: Shows the number of responses for question 1

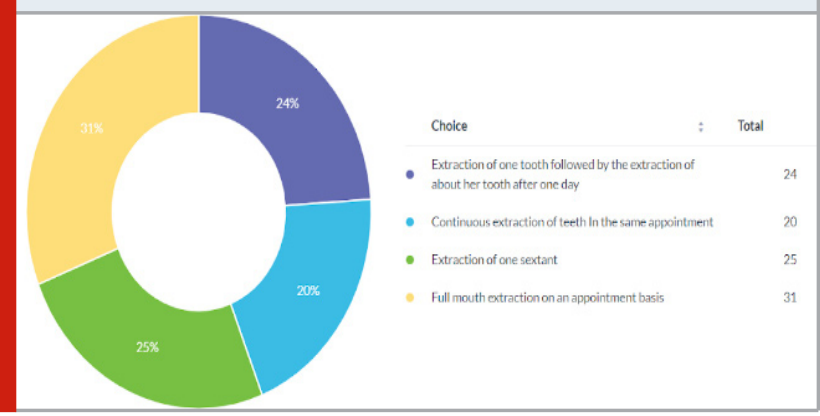

Graph 2: Shows the number of responses for question 2

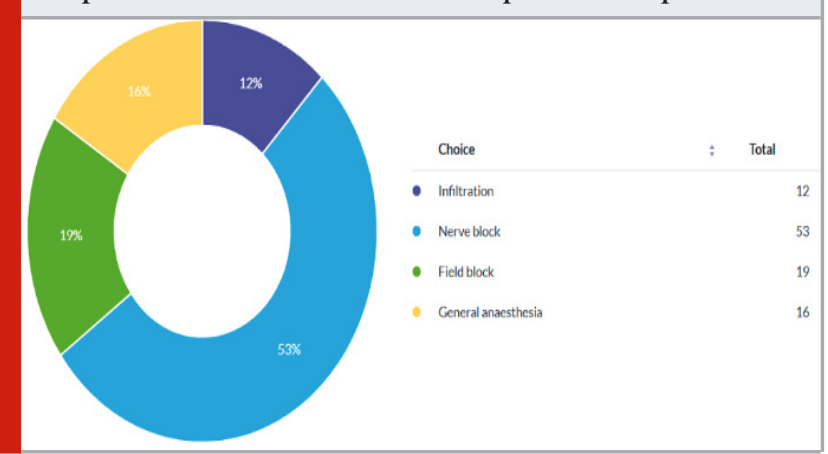

\section{RESULTS}

The results obtained were tabulated and represented by using a pie chart.

Graph 3: Shows the number of responses for question 3

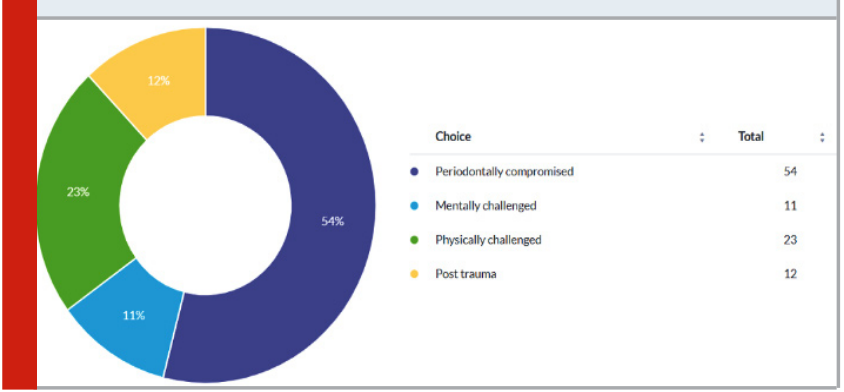

RESULTS AND DISCUSSION

Based on the results obtained, the following deductions were made. The first question required the students to define what serial extractions are. Graph 1 shows 31\% of the students are aware of its definition while 69\% of the students were not. Graph 2 shows 51\% of the students opted that serial extractions be done in the corrective stage of a dental procedure while $49 \%$ chose otherwise. Question 3 required the students evaluate which patient is more prone to serial extraction as a line of treatment. Based on graph 3,36\% of the students thought that 
patients undergoing prosthetic treatment are more prone to that line of treatment.

Graph 4 shows that $54 \%$ of the students opted that the deciduous molar should be the first tooth that should be extracted during a serial extraction, while $46 \%$ of the other students were torn between permanent incisors, deciduous incisors, and permanent molars. Graph 5 shows $47.7 \%$ of the students agreed that the main advantage of serial extractions is to improve arch space, $14.2 \%$ of them agreed that it provides space, while $38.1 \%$ agreed that both the options were apt.

Graph 4: Shows the number of responses for question 4

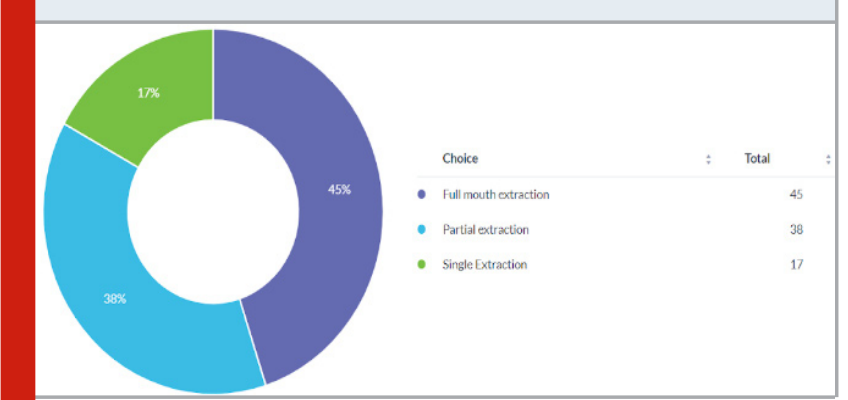

Graph 5: Shows the number of responses for question 5

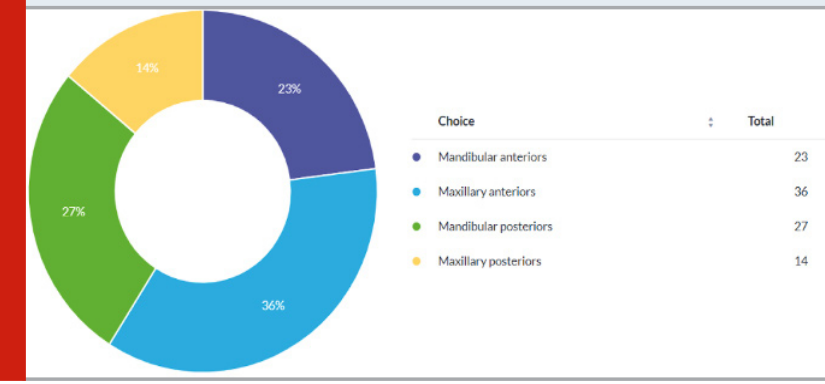

Question 6 asked if serial extractions should be recommended for patients with prosthetic teeth and 45\% of the students agreed while 38\% disagreed. In question 7 , the students were asked if they would recommend serial extractions as a line of treatment for their pediatric patients. $47.7 \%$ of them said yes while only $14.2 \%$ said no. Graph 8 shows that 51.3\% of the students agreed that serial extractions can be included in the treatment plan for patients with midline diastema while only $20 \%$ disagreed.

Graph 6: Shows the number of responses for question 6

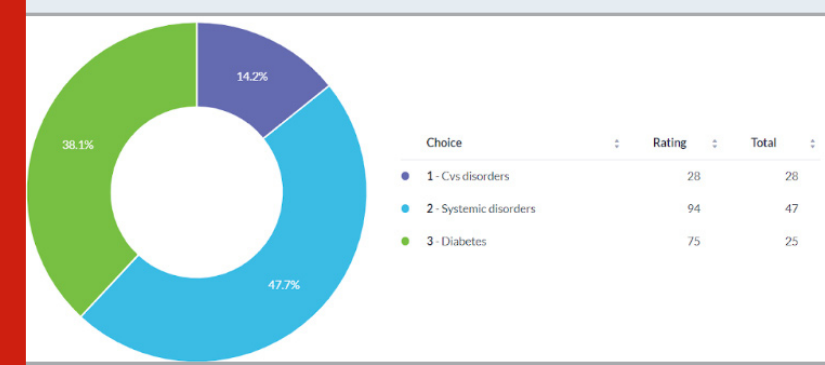

Graph 7: Shows the number of responses for question 7

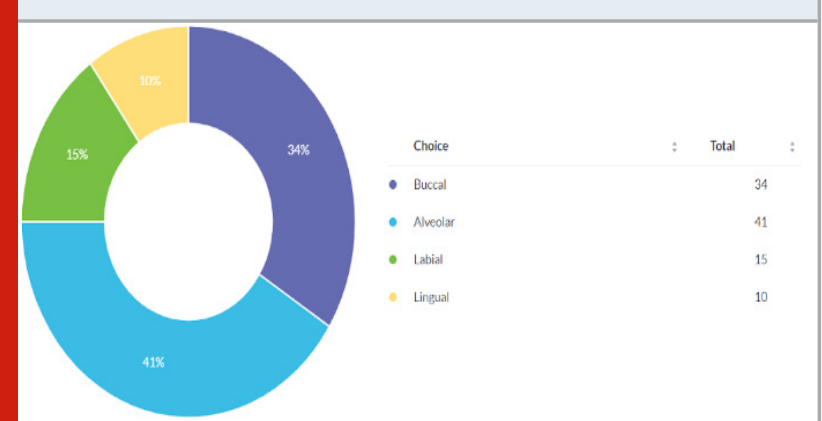

Graph 8: Shows the number of responses for question 8

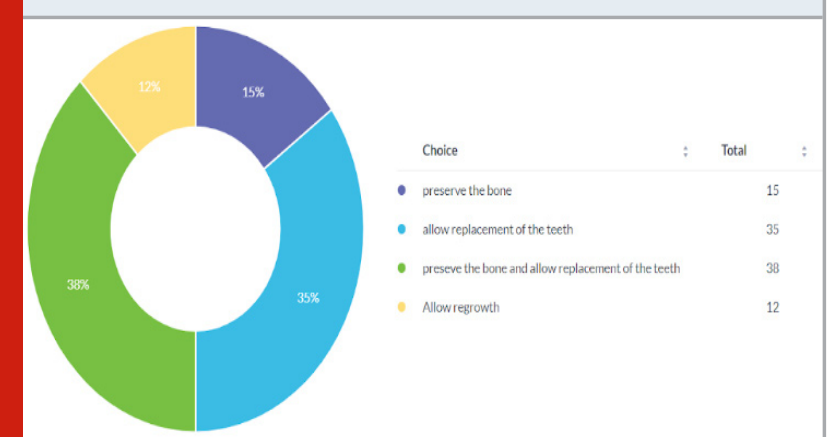

Question 9 was a question of true or false between two statements about the benefits of serial extractions. Graph 9 shows $35.5 \%$ of the students agreed on statement 2 , $33.1 \%$ agreed on statement $1,23.4 \%$ on both while $8.1 \%$ of them disagreed on both statements. Question 10 was a true or false question about whether or not serial extractions were apt for patients with more than one ankylosed teeth. Based on graph 10, 60\% of the students chose false while $40 \%$ chose true as an option. Serial Extraction, also known as the guidance of eruption, is an age-old procedure done to correct crowded arches and is usually done during the mixed dentition period(B.f.d and B., 1978). In other words, it is the planned and sequential extraction of certain deciduous teeth followed by the removal of specific permanent teeth in order to encourage the spontaneous correction of irregularities present(Bfd and Bfd, 1976).

Graph 9: Shows the number of responses for question 9

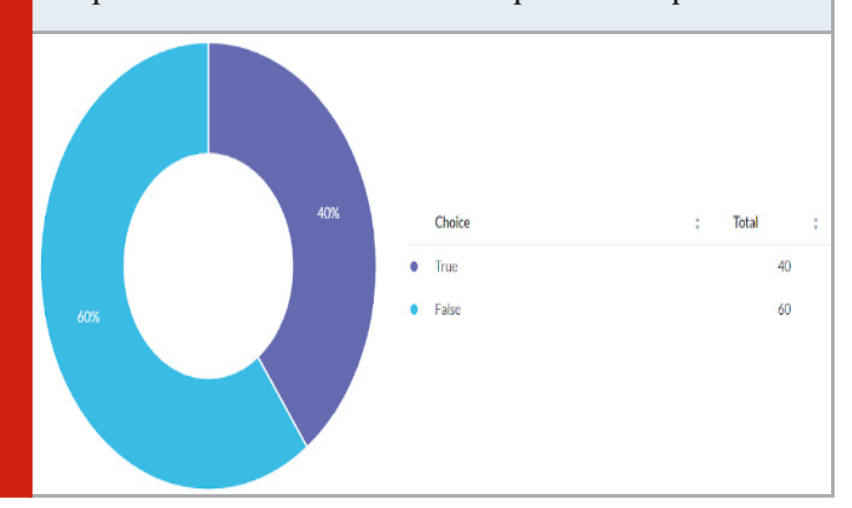


The patients who are most likely to be advised for serial extraction would be children going through a mixed dentition period with severe dental malocclusion and/ or crowding(Hinrichsen, 1961). As this procedure is an interruptive procedure done by the extraction of premolars and canines to better the arch shape and size, this procedure limits the types of patients to only dental orthopaedic treatment(Kaán, Kaán and Károlyházy, 2001).

Graph 10: Shows the number of responses for question 10

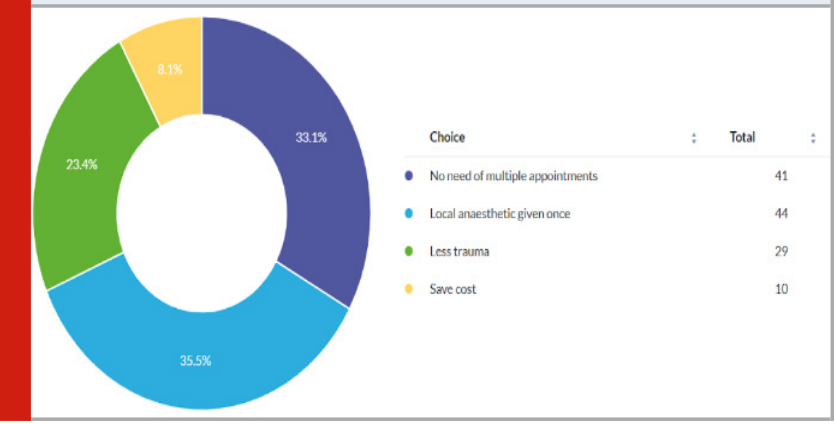

The first tooth to be extracted during a serial extraction treatment is the deciduous molar. All the deciduous predecessors of the molars are wider mesiodistally compared to the premolars of the second dentition('Serial Extraction', 2010). Therefore, if the second molar is lost, a significant drifting together of the adjacent teeth can begin before the permanent tooth provides a direct mechanical resistance, due to its size, shape and position(B.f.d and B., 1978). In cases of diastema, serial extraction should not be performed before the diastema is corrected. Diastema can either be between the central incisors or due to crowded erupting laterals(Bs, Phulari and Modley, 2017).

One of the many advantages of serial extraction include, a more stable and aesthetically pleasing result, teeth will erupt over the alveolus and through -keratinized tissue, rather than being displaced buccally or lingually(Marques et al., 2011). The cost of orthodontic treatment at a later stage will also be avoided. The health of the investing tissues is also preserved with less potential for iatrogenic damage like root resorption and enamel decalcification(Degering, 1965). The line of treatment for ankylosed teeth is orthodontic surgery(Pace, Murray and Sandler, 2010). Other treatments like, restorative or prosthetic would help the patient look pleasing(Graber, 1971). However, the patient would not feel comfortable.

\section{CONCLUSION}

In a nutshell, this survey has shun some light on the subject and although it is clear that most of them are aware about serial extraction, there are some who are still unclear about the concept and facts. More conferences, case presentation and activities regarding serial extraction, might help the undergraduates develop interest in this field and hopefully gain a little more knowledge about serial extractions.

\section{REFERENCES}

Anbu, R. T. et al. (2019) 'Comparison of the Efficacy of Three Different Bone Regeneration Materials: An Animal Study', European journal of dentistry, 13(1), pp. 22-28.

Ariga, P. et al. (2018) 'Determination of Correlation of Width of Maxillary Anterior Teeth using Extraoral and Intraoral Factors in Indian Population: A Systematic Review', World Journal of Dentistry, 9(1), pp. 68-75.

Ashok, V. and Ganapathy, D. (2019) 'A geometrical method to classify face forms', Journal of oral biology and craniofacial research, 9(3), pp. 232-235.

Bfd and Bfd (1976) 'Serial extraction: Precautions, limitations, and alternatives', American Journal of Orthodontics, pp. 95-97. doi: 10.1016/00029416(76)90102-0.

B.f.d and B., F. D. (1978) 'Serial extraction, second premolars, and diagnostic precautions', American Journal of Orthodontics, pp. 575-577. doi: 10.1016/00029416(78)90247-6.

Bs, P., Phulari, B. S. and Modley, D. (2017) ‘Management of Midline Diastema', Orthodontics: Principles and Practice, pp. 406-406. doi: 10.5005/jp/books/12999_38.

Bs, P., Phulari, B. S. and Naik, P. (2017) 'Classification of Malocclusions', Orthodontics: Principles and Practice, pp. 71-71. doi: 10.5005/jp/books/12999_9.

Degering, C. I. (1965) 'Adolescent enamel decalcification', Oral Surgery, Oral Medicine, Oral Pathology, pp. 321327. doi: 10.1016/0030-4220(65)90042-3.

Duraisamy, R. et al. (2019) 'Compatibility of Nonoriginal Abutments With Implants: Evaluation of Microgap at the Implant-Abutment Interface, With Original and Nonoriginal Abutments', Implant dentistry, 28(3), pp. 289-295.

Evaluation of Corrosive Behavior of Four Nickelchromium Alloys in Artificial Saliva by Cyclic Polarization Test:An in vitro Study' (2017) World Journal of Dentistry, 8(6), pp. 477-482.

Ganapathy, D. M., Kannan, A. and Venugopalan, S. (2017) 'Effect of Coated Surfaces influencing Screw Loosening in Implants: A Systematic Review and Meta-analysis', World Journal of Dentistry, 8(6), pp. 496-502.

Graber, T. M. (1971) 'Serial extraction: A continuous diagnostic and decisional process', American Journal of Orthodontics, pp. 541-575. doi: 10.1016/00029416(71)90197-7.

Gupta, P., Ariga, P. and Deogade, S. C. (2018) 'Effect of Monopoly-coating Agent on the Surface Roughness of a Tissue Conditioner Subjected to Cleansing and Disinfection: A Contact Profilometric Study', Contemporary clinical dentistry, 9(Suppl 1), pp. S122S126.

Hinrichsen, C. F. L. (1961) 'Serial extraction in mixed 
dentition orthodontics', Australian Dental Journal, pp. 201-209. doi: 10.1111/j.1834-7819.1961.tb04201.x. Jain, A. R. (2017a) 'Clinical and Functional Outcomes of Implant Prostheses in Fibula Free Flaps', World Journal of Dentistry, 8(3), pp. 171-176.

Jain, A. R. (2017b) 'Prevalence of Partial Edentulousness and Treatment needs in Rural Population of South India', World Journal of Dentistry, 8(3), pp. 213-217. Jayade, V. (2016) 'Possibility of space closure without initial alignment', Journal of Indian Orthodontic Society, pp. 132-132. doi: 10.4103/0301-5742.179950.

Joondeph, D. R. and Riedel, R. A. (1976) 'Second premolar serial extraction', American Journal of Orthodontics, pp. 169-184. doi: 10.1016/0002-9416(76)90195-0.

Kaán M., Kaán B. and Károlyházy K. (2001) ‘[Prosthodontic correction of severe deep vertical overbite combined with dimensional discrepancy of the upper and lower dental arch. 31 years follow-up]', Fogorvosi szemle, 94(2), pp. 63-68.

Kocyigit, S. et al. (2019) 'Are age and radiographic features effective on orthodontic alignment of palatally impacted maxillary canines? a retrospective study', European Oral Research, pp. 132-136. doi: 10.26650/ eor.20190055.

Kumar, P. (2007) 'Corrective Orthodontic Treatment', Synopsis of Orthodontic Treatment, pp. 40-40. doi: 10.5005/jp/books/10887_6.

Lian, A. and Karlsen, P. J. (2004) 'Advantages and disadvantages of phonological similarity in serial recall and serial recognition of nonwords', Memory \& Cognition, pp. 223-234. doi: 10.3758/bf03196854.

'Malocclusions, Dental' (2012) Clinical Veterinary Advisor, pp. 351-352. doi: 10.1016/b978-1-4160-99796.00485-2.

Marques, L. S. et al. (2011) 'Extraction of four premolars in Black patients with bi-protrusion: aesthetic perceptions of professionals and lay people', Journal of orthodontics, 38(2), pp. 107-112.

Meador, D. K. (1982) 'An investigation of the threedimensional force and moment design parameters of selected orthodontic alignment loops', American
Journal of Orthodontics, p. 439. doi: 10.1016/00029416(82)90207-x.

0'Shaughnessy, K. W. et al. (2011) 'Efficiency of serial extraction and late premolar extraction cases treated with fixed appliances', American journal of orthodontics and dentofacial orthopedics: official publication of the American Association of Orthodontists, its constituent societies, and the American Board of Orthodontics, 139(4), pp. 510-516.

Pace, A., Murray, A. and Sandler, J. (2010) 'Orthognathic surgery: 2. what is it all about?', Orthodontic Update, pp. 38-43. doi: 10.12968/ortu.2010.3.2.38.

Ranganathan, H., Ganapathy, D. M. and Jain, A. R. (2017) 'Cervical and Incisal Marginal Discrepancy in Ceramic Laminate Veneering Materials: A SEM Analysis', Contemporary clinical dentistry, 8(2), pp. 272-278.

Ringenberg, Q. M. (1964) 'Serial extraction: Stop, look, and be certain', American Journal of Orthodontics, pp. 327-336. doi: 10.1016/0002-9416(64)90174-5.

Salzmann, J. A. (1966) 'Serial extraction in general dental practice', American Journal of Orthodontics, pp. 145-146. doi: 10.1016/0002-9416(66)90005-4.

'Serial Extraction' (2010) Orthodontic and Dentofacial Orthopedic Treatment. doi: 10.1055/b-0034-78395.

Varghese, S. S., Ramesh, A. and Veeraiyan, D. N. (2019) 'Blended Module-Based Teaching in Biostatistics and Research Methodology: A Retrospective Study with Postgraduate Dental Students', Journal of dental education, 83(4), pp. 445-450.

Wagner, M. and Berg, R. (2000) 'Serial extraction or premolar extraction in the permanent dentition? Comparison of duration and outcome of orthodontic treatment', Journal of orofacial orthopedics = Fortschritte der Kieferorthopadie: Organ/official journal Deutsche Gesellschaft fur Kieferorthopadie, 61(3), pp. 207-216. Yoshihara, T. et al. (2000) 'Effect of serial extraction alone on crowding: Spontaneous changes in dentition after serial extraction', American Journal of Orthodontics and Dentofacial Orthopedics, pp. 611-616. doi: 10.1067/ mod.2000.110170. 